\title{
Intestinal Blood Loss Due to GIST
}

\author{
Jeroen Heemskerk $^{\mathrm{a}}$ Cor G.M.I. Baeten ${ }^{\mathrm{b}}$ \\ ${ }^{a}$ Department of Surgery, Catharina Ziekenhuis Eindhoven, Eindhoven, and ${ }^{\mathrm{b}}$ Department of Surgery, \\ Maastricht University Hospital, Maastricht, The Netherlands
}

A 35-year-old anemic man presented with fainting, black sticky defecation and rectal blood loss since one day. He had a pulse of $90 \mathrm{bpm}$ and a blood pressure of 100/70 mm Hg. The abdomen was painless and did not show any palpable masses. Rectal examination confirmed the presence of melena.

Laboratory findings showed a hemoglobin level of $9.3 \mathrm{~g} /$ $\mathrm{dl}$ and a hematocrit of 0.28 liters/liter. Esophago-gastroduodenoscopy showed grade one esophagitis without blood or potential cause for bleeding. Colonoscopy was not performed due to the presence of voluminous stools.
Despite transfusion, hemodynamics worsened and hemoglobin level decreased to $8.2 \mathrm{~g} / \mathrm{dl}$. Seldinger angiography of the superior mesenteric artery showed an arterio-venous malformation in the jejunum (arrow). During laparotomy a $5.5-\mathrm{cm}$ gastrointestinal stromal tumor was excised with free resection margins. The patient recovered uneventfully and 5 years after resection our patient is in excellent condition with no signs of recurrence.

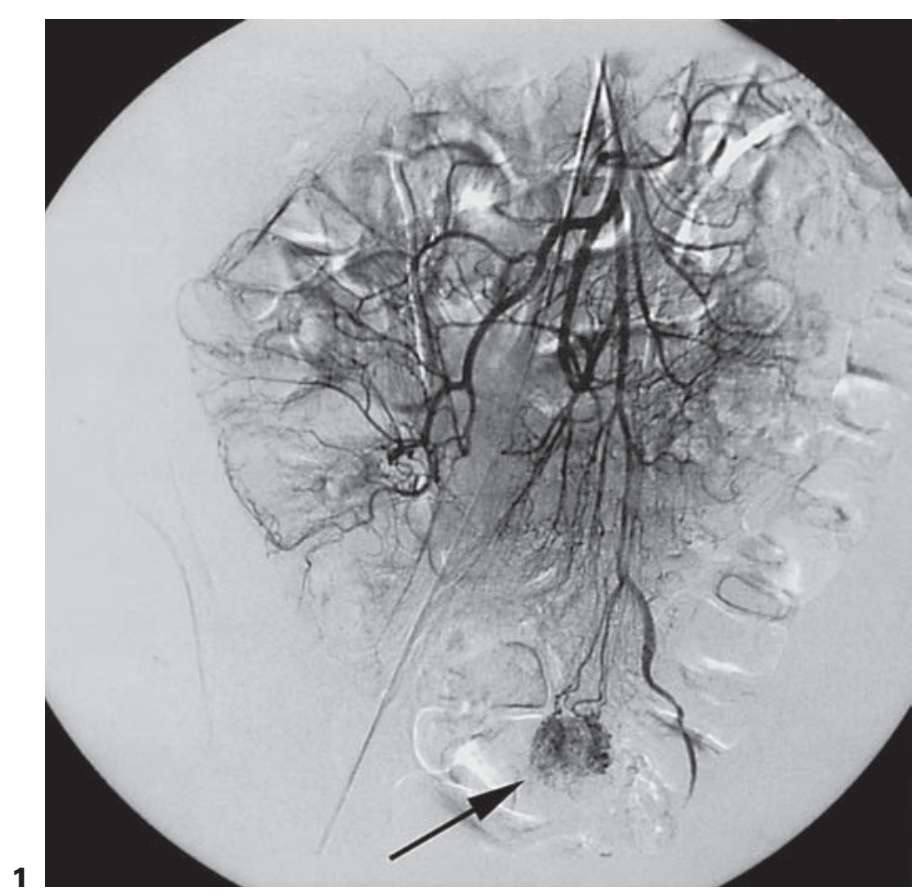

\section{KARGER}

Fax +41613061234 E-Mail karger@karger.ch www.karger.com

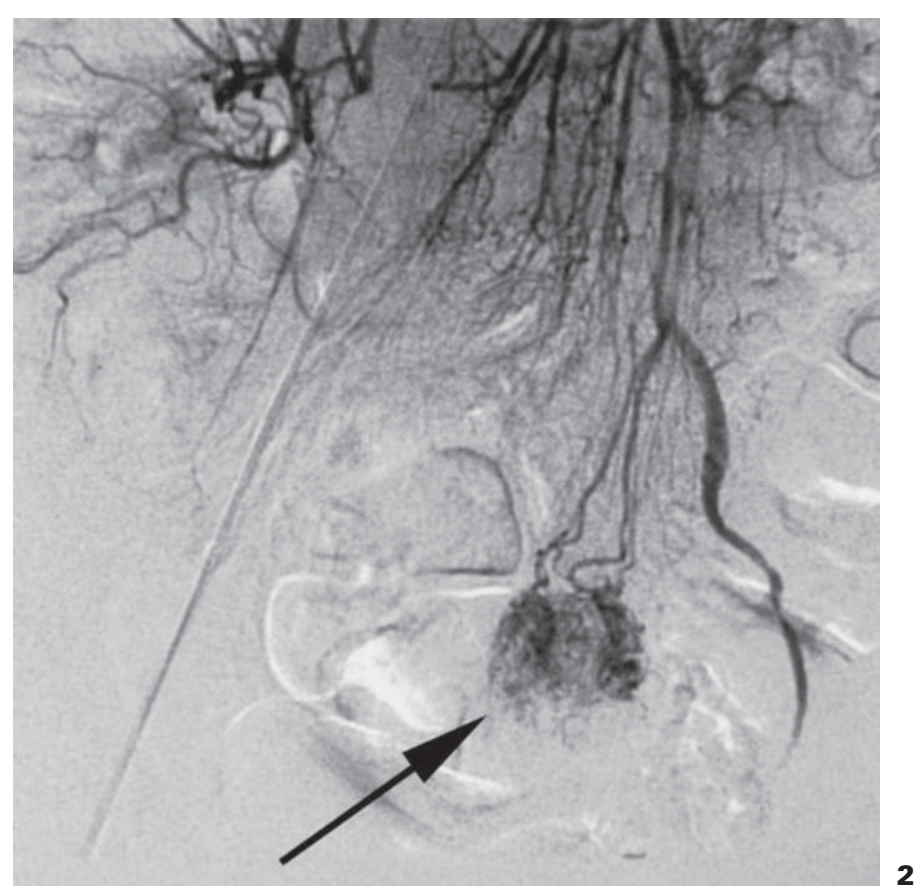

Jeroen Heemskerk, MD

Department of Surgery

Catharina Ziekenhuis Eindhoven, Michelangelolaan 2

NL-5602 AZ, Eindhoven (The Netherlands)

Tel. +31 402399 111, Fax +31 402443 370, E-Mail heemsch@hetnet.nl 